\title{
ENZYMATIC STUDIES OF RADIATION DAMAGE
}

Progress Report

M. Laskowski, Sr.

Roswell Park Memorial Institute Buffalo, New York

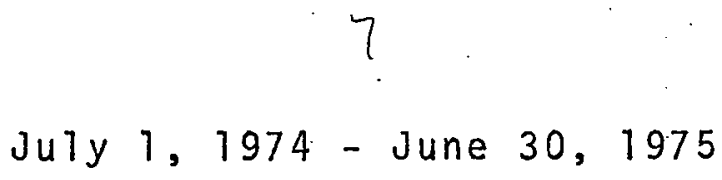

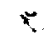

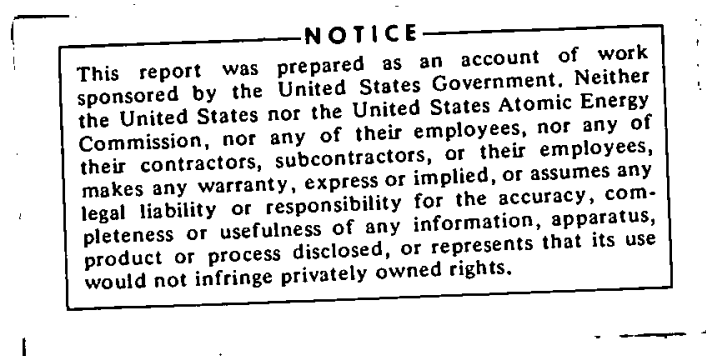




\section{DISCLAIMER}

This report was prepared as an account of work sponsored by an agency of the United States Government. Neither the United States Government nor any agency Thereof, nor any of their employees, makes any warranty, express or implied, or assumes any legal liability or responsibility for the accuracy, completeness, or usefulness of any information, apparatus, product, or process disclosed, or represents that its use would not infringe privately owned rights. Reference herein to any specific commercial product, process, or service by trade name, trademark, manufacturer, or otherwise does not necessarily constitute or imply its endorsement, recommendation, or favoring by the United States Government or any agency thereof. The views and opinions of authors expressed herein do not necessarily state or reflect those of the United States Government or any agency thereof. 


\section{DISCLAIMER}

Portions of this document may be illegible in electronic image products. Images are produced from the best available original document. 


\section{ANNUAL PROGRESS REPORT CO0-3225-10}

\section{ATOMIC ENERGY COMMISSION}

Title:

Enzymatic Studies of Radiation Damage

Institution:

Roswe 11 Park Memorial Institute

Leader:

M. Laskowski, Sr., Ph.D.

Head, Laboratory of Enzymology,

American Cancer Society Research Professor

Publications:

COO-3225-11

Kedzierski, W., Laskowski, M., Sr. and Mandel, M., "Mung Bean Nuclease I. V. A Tool for Probing Low Melting Regions in Deoxyribonucleic Acid", J. Biol. Chem. 248, 1277 (1973).

$\mathrm{C} 00-3225-12$

Duch, D.S., Borkowska, I., Stasiuk, L. and Laskowski, M., Sr., "Identification öf Both

Termini of an 01 igonucleotide in a Nanomole Quantity", Aria 1. Biochem. 53, 459 (1973).

$\mathrm{C} 00-3225-13$

Laskowski, M., Sr., "Some Thoughts on Classification of Nucleases", G.P. Murphy, edt.; Perspective in Caricer Research and Treatment, Alan R. Liss, New York, p. 365 (1973). Review Article.

Activities other than research:

1. I was elected to Honorary Membership of the Polish Biochemical Society during the $X$ Annual Meeting in Poznan, Poland, September 1972. I delivered there an opening lecture entitled: "Region Specific Nucleases".

2. I was a receipient of the Schoellkopf medal, awarded by the Western New York section of the American Cancer Society, May, 1973. The work on nucleolytic enzymes was cited.

3. I was a chairman and a speaker during the II International Conference on Proteinase Inhibitors at Grosse Ledder near Cologne, Germany (October 1973). 
Summary

Three papers have been published. Mung bean nuclease was shown to excise the $A+T$ rich regions from different species of DNA exposed to premelting temperatures. This suggests an additional application of mung bean nuclease as a means of detection of slightly damaged regions of DNA. A new sensitive method for the determination of nucleoside monophosphates and nucleoside $3^{\prime}$, 5'-diphosphates was developed. The method was applied to the determination of the frequency of nucleosides appearing in the terminal position of an oligonucleotide. An argument (polemics) in favor of the classification of nucleases that preserves biological unity of all nucleases has been presented. 
Research

The large number of papers listed in last year's report is not likely to be repeated in the near future. It was caused by unloading of a backlog accumulated during the preceding years. The reduction of funds resulted in the reduction of personnel from two to one post-doctoral associates, and, consequently, resulted in a decrease in productivity, measured in quantity of published papers. The most dangerous aspect of the personnel reduction deals with the choice of personnel. Under the present conditions one error in selection means a 100\% $10 \mathrm{ss}$.

The three papers published this year probably represents an average to be expected for the forseeable future.

Pursuing the breakthrough described last year caused by isolation of mung bean nuclease $I$, we attempted to utilize this enzyme as probe of locating the $A+T$ rich regions in different DNAs. The results of this investigation are described in document c00-3225-11. DNAs with different composition, ranging from $A+T$ rich to $A+T$ poor were prepared from several bacterial and animal sources. Each DNA was then subjected to digestion with a modest dose of mung bean nuclease, insufficient to attack the double stranded regions. About $2-3 \%$ of DNA was rendered acid soluble. We think that this susceptible DNA, which we find in all preparations, represents partially denatured portions of the molecule, presumably located at termini damaged in process of isolation. Interestingly and unexpectedly, we also found that a large portion of contaminating RNA is rendered acid soluble during 
this treatment. This finding has been discussed in detail in the last year report, because it offers a chance of devising a method for removing the contaminating RNA without damaging DNA. This finding came about because of the newly developed method capable of distinguisting deoxyribonucleosides from ribonucleosides (document (00-3225-4, reported last year). Whether I ever will find time to work out the detailed set of conditions for this purpose I do not know. A number of other issues seem to be more pressing. The DNA preparation described above which was predigested with mung bean nuclease was then exposed to a premelting temperature that produced about $10 \%$ of the total hyperchromic effect. After this exposure the sample was incubated with mung bean nuclease for 30 minutes and the DNA was precipited with alcohol. The alcohol soluble material was richer in $A+T$ than the parent DNA from which it was obtained, regardless whether the parent DNA belonged to $A+T$ rich or $A+T$ poor group. The alcohol soluble products were then chromatographed according to the method of Junowicz and spencer to segregate them according to length. The results showed that the fragments were composed of short 01 igonucleotides varying in length from mono- to tetranucleotide. These results did not allow one to decide which of the two alternative mechanisms is applicable to mung bean nuclease. The first alternative is that a fragment rich in $A+T$ is first excised and then degraded to a mixture of short oligonucleotides. Another alternative is that a single opening is induced in DNA and is followed by the release of small oligonucleotides until the heavily double stranded region is encountered. Should the first alternative be 
true, no effort should be spared to prove it. Isolation of an excised fragment of the order of a 50-mer would be of great value in the understanding of the detailed structure of DNA. We are now studying the effect of $\mathrm{Mg}^{++}$on the production of short fragments by mung bean nuclease with the hope that it would be possible to specifically inhibit their formation, without preventing the excision of a large fragment. We are also looking at the population of large fragments (alcohol insoluble) to evaluate the effect of $\mathrm{Mg}^{++}$. Sieving through sepharose was too crude a method to allow any conclusions. We are now using gel-electrophoresis which appears promising.

I mentioned previously that studying the action of mung bean nuclease appeared promising as to eliminate heterochromatin from the intact chromosome. Our laboratory is not equipped for such a study. We delivered large amounts of enzyme to be tested on chromosomes during the spindle phase. The reports that came back were erratic. Some showed digestion of heterochromatin region, but an equal or higher number of experiments was negative. In view of the erratic results and the quantity of enzyme that is required, this 7 ine of inquiry was suspended.

The document c00-3225-12 is a detailed paper of the abstract c00-3225-06 discussed last year. The methodological work was conceived as a complementary paper to c00-3225-04, which described the method of analys is of nucleosides ( $r i b o-$ and deoxyribo-). The method turned out to be popular, and is expected to remain so for some time to come.

If one considers that any oligomer can be degraded by an 
exonuclease to a mixture of a nucleoside (one terminus), several mononucleotides, and a nucleoside $3^{\prime}, 5^{\prime}$-diphosphate (second terminus), the availability of a good method for the determination of diphosphates is important. Since a good method for nucleosides (c00-3225-04) exists, we worked on the complementory method and reported it at federation (c00-3225-06). Then a calamity came; the type of resin for which the conditions were worked out was discontinued, and using a resin from a different company we were unable to repeat our own work. At the time of writing the previous report, we were desperately trying to modify the conditions to fit the new resin. This finally was accomplished and the results were sufficiently good to publish (c00-3225-12). Since that time, a considerable further improvement in analytical accuracy has been achieved, but these results have not yet been published. Unfortunately, we also found out the limitations to the method which appeared applicable to all oligonucleotides regardless of length. With oligonucleotides bearing $5^{\prime}$-monophosphate $\mathrm{pN}^{\alpha} \mathrm{p}(\mathrm{Np}){ }_{n} \mathrm{~N}^{\omega}$, we used micrococcal nuclease in very high doses (half-saturated solution of enzyme) to obtain quantitatively $p N^{\alpha} p+n(N p)+N^{\omega}$. It worked well with di-, tri-, tetra-, and pentanucleotides. When we applied the same method to a chain of 20 -mer, the reaction did not go to termination. We knew, of course, that $\mathrm{pN}^{\alpha} \mathrm{p}$ is inhibitory; to overcome this we used the excessive amount of enzyme. Onty one $\mathrm{pN}^{\alpha} \mathrm{p}$ is liberated whether a penta- or a decamer is used. What was different is a number of dinucleotides. With a 20-mer several dinucleotides are formed by the endonucleolytic action. These dinucleotides are sufficiently resistant to increase the demand for 
enzyme beyond the practically achievable limits (unpublished).

I still think that the purity of micrococcal nuclease is exceptionally high to compare with other avajlable 3 'monoester formers, making it the enzyme of choice. This choice, however, must be limited to oligonucleotides shorter than pentamers. However, for longer fragments a different enzyme or enzymes must be found to accomplish a complete degradation, without introduction of interfering contaminants.

The opposite case, the analysis of termini in an oligomer bearing $3^{\prime}$-monophosphate $N^{\alpha}(p N)_{n} p N^{\omega} p$ with the aid of venom exonuclease, does not seem to be as adversly affected by the length of the oligomer, as was the previous case. The inhibition by the products is not as serious and chains of the size of 20-mers appear to be appropriate substrate. However, the purity of venom exonuclease is not as high as that of micrococcal nuclease. The removal of the remaining traces of monophosphatases is a very difficult task. Recently, we have found that venom exonuclease is a glycoprotein and is strongly absorbed by Concanavalin-ASepharose column. The nonspecific phosphatase is also absorbed, butcan be eluted with $0.1 M$ a-methyl-D-mannoside, while exonuclease cannot. The immobilized preparation of venom exonuclease appears to be promising because the enzyme is highty purified and relatively stable (unpublished).

A year ago, Dr. M. Yamamoto, Vancouver, Canada, came to our laboratory for six months of his sabbatical leave. He brought with him a preparation of a highly purified DNase from salmon testes. There were reasons to believe that this enzyme may have 
an interesting base specificity, and it was decided to study this problem. The enzyme forms products bearing 3'-monophosphate, and only reluctantly forms short fragments.(mono- to tetra-). The newly described analytical methods (documents c00-3225-04 and-12) were used for the determination of frequency at terminal positions. The results showed that $G$ was the most common and $T$ was the least common at both termini. Unfortunately, the amount of nucleosides obtained was higher than the amount of diphosphates by about $30 \%$. The most rigorous controls accounted for a maximum dephosphorylation of $6 \%$, as due to contaminating monophosphatase in venom exonuclease, and of $0.1 \%$ as due to monophosphatase in salmon testes DNA. The discrepancy must therefore be ascribed to the analytical difficulties. The measurements were done at the period of difficulties of switching from one supplier of resin to another. The results, which are interesting, still remain unpublished.

The document $000-3225-13$ is a review article. It was pub1 ished in book commemorating the 75 th anniversary of Roswell Park Memorial Institute. It attacks the accepted classification of nucleases on the ground of being impractical. The cyclizing RNases are assigned to the group of transferases, al1 other RNases, DNases, and sugar unspecific nucleases are assigned to hydrolases. I pointed out that this classification disregards the biological role, that the cyclic stage exists in which the intermediate form is very short lived. No one in the past few years succeeded to write a review on RNases limited only to transferases. I suggested that a classification which has lost practical usefulness should be changed. Frankly, I do not think that this article will have serious con- 
sequences. First, because it will be read by a limited number of people. Second, it is always very difficult to change an existing system even after its inadequacy becomes apparent. 